
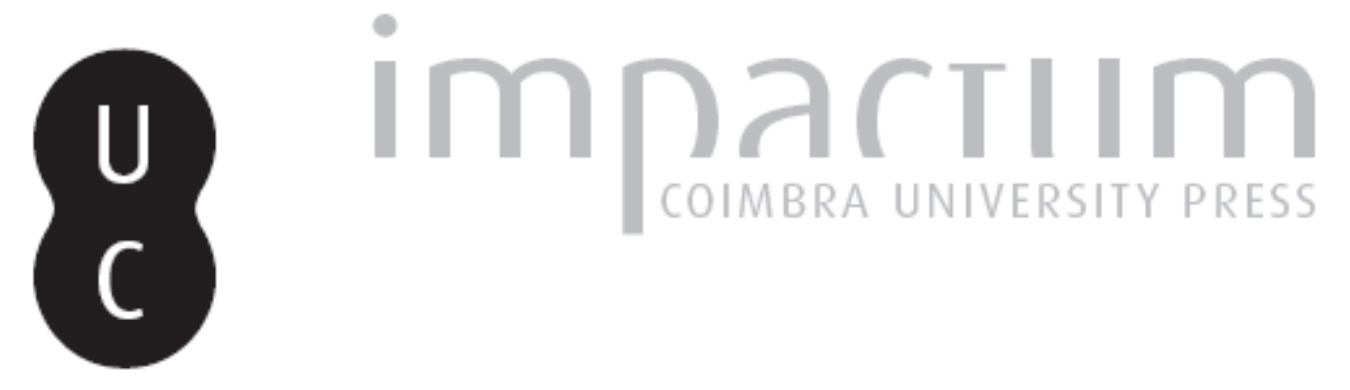

\title{
Pessimismo literário na disputa sobre o suicídio e na morte de Enkidu
}

Autor(es): Martins, Ivo

Publicado por: Centro de História da Universidade de Lisboa

URL persistente:

URI:http://hdl.handle.net/10316.2/32974

DOI:

DOI:http://dx.doi.org/10.14195/0871-9527_22_3

Accessed : $\quad$ 26-Apr-2023 13:30:26

A navegação consulta e descarregamento dos títulos inseridos nas Bibliotecas Digitais UC Digitalis, UC Pombalina e UC Impactum, pressupõem a aceitação plena e sem reservas dos Termos e Condições de Uso destas Bibliotecas Digitais, disponíveis em https://digitalis.uc.pt/pt-pt/termos.

Conforme exposto nos referidos Termos e Condições de Uso, o descarregamento de títulos de acesso restrito requer uma licença válida de autorização devendo o utilizador aceder ao(s) documento(s) a partir de um endereço de IP da instituição detentora da supramencionada licença.

Ao utilizador é apenas permitido o descarregamento para uso pessoal, pelo que o emprego do(s) título(s) descarregado(s) para outro fim, designadamente comercial, carece de autorização do respetivo autor ou editor da obra.

Na medida em que todas as obras da UC Digitalis se encontram protegidas pelo Código do Direito de Autor e Direitos Conexos e demais legislação aplicável, toda a cópia, parcial ou total, deste documento, nos casos em que é legalmente admitida, deverá conter ou fazer-se acompanhar por este aviso.

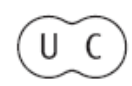



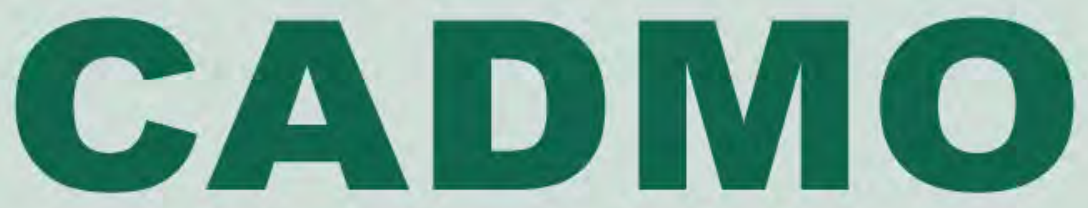

Revista de História Antiga

\author{
Centro de História \\ da Universidade de Lisboa
}

\title{
22
}

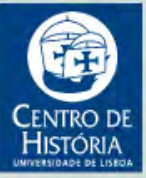

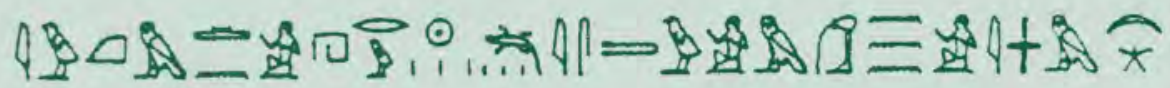

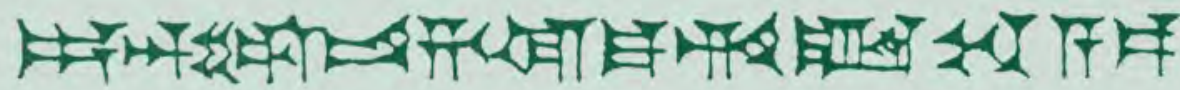
MHNIN AEI $\Delta \mathrm{E} \Theta \mathrm{EA} \Pi \mathrm{\Pi H} \Lambda \mathrm{HIA} \Delta \mathrm{E} \Omega$ 


\section{PESSIMISMO LITERÁRIO NA DISPUTA SOBRE O SUICÍDIO E NA MORTE DE ENKIDU}

IVO MARTINS

Universidade de Lisboa ivomartins@campus.ul.pt

\section{Introdução}

A finalidade deste trabalho é a análise da presença do fenómeno de pessimismo literário em duas composições literárias pré-clássicas: uma de proveniência egípcia; outra de proveniência mesopotâmica.

A análise levará em consideração três aspectos: o conceito de «pessimismo literário»; as concepções de cariz antropológico e escatológico que concorrem na formulação do pessimismo literário; e a heterogeneidade e, não obstante, o paralelismo dos contextos de produção.

Pessimismo é, no sentido elementar do termo, uma perspectiva extremada e tendencialmente negativa que se sustenta perante uma experiência, um acontecimento ou um conceito. Trabalhando sobre textos do âmbito da literatura sapiencial, este pessimismo torna-se um recurso estilístico, e acha-se afecto a uma dada finalidade ou a um dado objectivo. Sobre o conceito de pessimismo literário e a sua presença nas composições em estudo elaboraremos no ponto IV.

Ao longo dos textos, certas concepções fundamentais para a compreensão da mentalidade egípcia e da mentalidade mesopotâmica contribuem para o discurso do pessimismo literário e são manifestas no jogo argumentativo entre a implementação e a superação desse pessimismo literário. Para que se possa compreender devidamente qualquer 
das composições e a mecânica do pessimismo literário é necessário abordar o conceito de condição humana, o qual abrange concepções antropogónicas e escatológicas. Abordaremos este conceito no ponto III.

De modo a ensaiar uma hipótese explicativa sobre a origem do pessimismo literário e o seu impacto sobre as composições em estudo, contextualizaremos o processo produtivo e apresentaremos cada fonte no ponto II. Por fim, concluiremos o presente estudo com o resumo sucinto das conclusões alcançadas no ponto $V$. As informações bibliográficas e heurísticas figurarão no fim do artigo devidamente indexadas.

\section{Fontes: apresentação e contextualização}

O presente trabalho analisa o fenómeno de pessimismo literário na composição egípcia Disputa Sobre o Suicídio e na composição mesopotâmica Morte de Enkidu.

Cada uma destas fontes possui uma morfologia específica e são igualmente fruto de um contexto de produção próprio, tornando indispensável a devida apresentação formal e contextualização histórica de cada composição e do respectivo processo produtivo.

A composição egípcia é intitulada Disputa sobre o Suicídio na tradução em que nos baseamos ${ }^{(1)}$. Outras traduções sugerem outros títulos: Diálogo do cansado da vida com o seu $\mathrm{Ba}^{(2)}$, A disputa entre um homem e o seu $B a^{(3)}$. Os autores franceses parecem enveredar também por esta opção, se bem que prefiram usar o termo de «desesperado» ou "desiludido» (4) ao invés de «cansado».

Esta diferenciação não é inocente, ela traduz uma evolução na interpretação do texto: de uma interpretação literal, que toma o suicídio como tema central, a composição passou a ser interpretada como um debate sobre concepções escatológicas.

A Disputa sobre o Suicídio é por nós conhecida através do Papiro de Berlim 3024, o qual se apresenta lacunar. Entre pequenas lacunas intralineares e passíveis de reconstituições seguras, o papiro contém uma lacuna inicial de substancial extensão que se não presta a qualquer reconstituição. Restaram intactas cerca de 155 colunas nas quais se reconhecem três registos literários: prosa, discurso simétrico e poesia lírica.

Trata-se de uma unidade narrativa independente que se desenvolve na relação dialéctica entre duas personagens: o «homem» ou «eu» e a 
«alma» ou «Ba». Estas personagens confrontam-se num jogo argumentativo (cujo inicio se perdeu) que se encerra num compromisso de meio-termo.

Por seu turno, a Morte de Enkidu não é uma unidade narrativa independente; é uma das doze tabuinhas ${ }^{(5)}$ que constituem a Epopeia de Gilgameš, é, mais especificamente, a sétima tabuinha.

Dentro da linha narrativa da Epopeia de Gilgameš esta sétima tabuinha representa um ponto de viragem essencial. De uma vida de herói epicurista, compenetrado apenas na perseguição de riquezas e façanhas grandiosas, Gilgameš, transtornado pela perda do seu companheiro Enkidu, envereda por uma vida de herói estóico em demanda do segredo da vida eterna.

Assim a sétima tabuinha, ao retratar a agonia de um Enkidu moribundo, marca a transição dramática da personalidade de Gilgameš e isso, por consequência, torna-a preponderante na compreensão integral da Epopeia de Gilgameš.

A Morte de Enkidu é hoje conhecida por intermédio de múltiplas versões da Epopeia de Gilgameš incluindo, por exemplo, uma versão em prosa de proveniência hitita, a qual permitiu a reconstituição de algumas lacunas menores ${ }^{(6)}$. Contudo, a tabuinha apresenta ainda lacunas de larga extensão, nomeadamente uma lacuna inicial de trinta e cinco linhas ${ }^{(7)} \mathrm{e}$ uma lacuna final de cerca de trinta linhas.

Devido à lacuna final, a tabuinha não descreve de facto a morte de Enkidu. Aquilo que descreve é a angústia crescente de Enkidu com a aproximação da morte. O crescendo é alimentado pelo relato que Enkidu faz de dois sonhos acerca da sua morte. O primeiro sonho retrata a assembleia divina que decide a morte de Enkidu; o segundo sonho faz a premonição da morte de Enkidu e uma descrição sumária do Inframundo. Entre estes dois sonhos, Enkidu desenvolve um «monólogo» de lamentações e de maldições, interrompido esporadicamente por intervenções de Gilgameš e de Šamaš. Como veremos, estas três personagens vão entrar num jogo argumentativo que impelirá a demanda de Gilgameš.

À semelhança da morfologia, também os contextos históricos de produção das duas composições são diferenciados. Quer pelo afastamento cronológico e espacial desses contextos, quer pelo modo como foram produzidas as composições.

O modo de produção influiu na diferenciação das composições e dos seus contextos, na medida em que ditou um período de produção mais e menos alargado. A composição egípcia conheceu uma produção circunscrita 
(XII dinastia 1938-1759 a. C.), a composição mesopotâmica formou-se por meio de um processo produtivo plurissecular (2300-650 a. C.).

Por outro lado, existem elementos que aproximam os dois contextos históricos. Em primeiro lugar, as condições geomorfologicas similares entre ambas as regiões de produção: o deserto estéril cerceando vales férteis.

Estas realidades, presentes tanto na mentalidade egípcia, quanto na mentalidade mesopotâmica criam paralelismos entre as composições e auxiliam a implementação do «pessimismo literário».

Em segundo lugar, a ocorrência de períodos de instabilidade política e social no horizonte histórico recente de cada composição terá contribuído para uma maior aproximação temática. A composição egípcia, por ter um horizonte produtivo melhor definido, facilita a identificação de um período histórico preciso: o Primeiro Período Intermediário (c.2180-2040 a.C.).

A composição mesopotâmica, por sua vez, torna mais difícil a identificação de um período específico. Difícil, não por carência de períodos de instabilidade na cronologia mesopotâmica, mas exactamente pela sua abundância.

Para qualquer das três principais fases de produção da Epopeia de Gilgameš, poderemos indicar um período de instabilidade próximo. As conquistas de Sargão e Naramsin ou as invasões dos Gútios (c.2200-2100 a. C.) para a fixação dos poemas sumérios sob Šulgi de Ur III (2094-2047 a. C.); as infiltrações dos amorreus, o saque hitita de Babilónia ou a instalação dos cassitas em relação à versão medio-babilónica de Sîn-leqe-uninni, podem fornecer o contexto histórico com a instabilidade necessária para dotar a mentalidade mesopotâmica das dúvidas, das incertezas e das imagens suficientes ao florescimento do pessimismo literário.

Tanto o Primeiro Período Intermediário egípcio como os períodos de instabilidade no contexto mesopotâmico deram origem a vazios políticos, administrativos e jurídicos, a desnortes sociais e à desvalorização de valores morais antigos.

\section{A condição humana}

De uma maneira geral, para os contextos civilizacionais pré-clássicos os conceitos de homem, e de condição humana não podiam ser dissociados da totalidade do real nem podiam ser fraccionados em parcelas constitutivas. Perante isto, é natural que o conceito de condição humana esteja envolvido na linguagem do pessimismo literário. Decorre que ao 
moldar a linguagem do pessimismo literário imprime-lhe as especificidades do contexto cultural e religioso onde o mesmo conceito se define.

O conceito de condição humana no Egipto Antigo é complexo. A mitologia egípcia atribui a antropogonia à geração espontânea: o homem nasce das lágrimas do demiurgo (Atum, Ré ou Khepri consoante a cosmogonia de referência).

A constituição do homem encontra-se de certo modo sistematizada por via do estudo das concepções escatológicas egípcias. Segundo estas concepções e as práticas funerárias, o homem era um composto de elementos e princípios espirituais que se separavam no momento da morte. Entre vários elementos de menor relevância, a comunidade antropológica era constituída por quatro elementos principais: corpo, ka, ba e akh.

O corpo era fundamentalmente o suporte material da comunidade antropológica, devia ser preservado por modo a permitir a sobrevivência dos restantes elementos. O ka, conhecido como "duplo» por ser representado em duplicação do faraó, é a força vital. Quando o homem morria, o ka transferia-se para a sua estátua funerária, na qual, através da «falsa porta» recebia as oferendas do culto de sustento assegurado pelos herdeiros.

Por sua vez, o ba é um espírito ou génio divino dentro do homem, sendo representado por uma ave, com liberdade de movimentos.

Por último, o akh seria a glorificação de defunto após ter passado pelo julgamento de Osíris.

Sendo uma comunidade antropológica, gerada pelo demiurgo no decurso da criação do cosmos, a vida do homem egípcio seria a procura da harmonia, do equilíbrio interior e do equilíbrio cósmico, segundo o princípio da maet. Este equilíbrio devia ser procurado também na morte. Os rituais funerários egípcios tinham por objectivo garantir essa harmonia. Esta procura do equilíbrio está bem representada na balança de Tot que pesa o coração do defunto.

Para a personagem «eu» o pessimismo está também na perda desse equilíbrio, na possibilidade do seu ba o abandonar e, assim, o condenar a uma segunda morte.

No contexto mesopotâmico, a antropogonia é concebida como criação. Uma criação que segue o plano imaginado por Enki/Ea e tem por objectivo o suprimento de uma determinada necessidade. Criado a partir dos restos mortais de um deus revoltoso e da argila, o homem é pensado, criado para trabalhar pelos deuses. 
Para o homem mesopotâmico, a vida tinha em si o ónus do serviço aos deuses, era o destino que lhe estava decretado. Estando subordinado aos deuses em todos os aspectos, está-lhes subalternizado pelos limites da condição: o homem tem uma vida mortal; aos deuses pertence a vida imortal.

Ao morrer, o homem mesopotâmico não espera uma segunda vida que o recompense da vida de servidão que já viveu. Nem tão pouco pensa na morte como fuga a essa realidade, a morte assusta-o. O morto divide-se em duas entidades, o corpo material e o eţemmu que é o seu espírito ou fantasma.

O corpo tornado ossos é inumado, e passa a receber o culto funerário de sustento. O eţemmu desce ao Irkala onde conhece uma existência melancólica com melhores ou piores condições consoante os seus restos recebem o devido culto e o seu nome é rememorado ou não pelos seus descendentes. De qualquer modo, a existência deste espírito é sempre negativa, porque vazia dos prazeres da vida terrena.

Por esta razão, o pessimismo literário na Mesopotâmia nunca se socorre da morte como possível saída para as injustiças da vida.

\section{Pessimismo literário}

Em ambas as composições literárias o pessimismo está presente. Esta presença é denunciada, em primeiro lugar, pela entoação negativa construída ao longo do texto mediante escolhas de vocabulário.

Em segundo lugar, o pessimismo literário manifesta-se pelo conteúdo narrativo, o qual se concentra em três posições: na desvalorização de experiências passadas, na exacerbação das situações presentes e na recusa de esperanças futuras.

No entanto, estas três posições de pessimismo literário podem subsistir durante toda a linha narrativa. Uma ou duas destas posições terão que ser forçosamente refutadas ou abaladas para criar espaço para o mecanismo de superação actuar.

De facto, os intervenientes secundários actuam na linha narrativa contrapondo os argumentos pessimistas que o protagonista desenvolve.

Na Disputa sobre o Suicídio, este jogo argumentativo é dominado por um duplo pessimismo colocado em confrontação. Por um lado, o «Eu» professa um pessimismo em relação à situação presente que vive, a par de uma esperança onírica que coloca na vida depois da morte: 
«A quem posso falar eu hoje?

O pecado que espezinha a terra, Não tem fim.

A morte está hoje no meu olhar

(Como) a convalescença de um doente,

Como sair para campo aberto depois da clausura.»(8)

Por outro lado, o ba contrapõe invertendo, por via do mesmo pessimismo, a relação valorativa entre vida e morte e depreciando as concepções escatológicas acarinhadas pelo «eu»:

«Aqueles que constroem em granito e talham câmaras em uma pirâmide, bons homens em bom trabalho, assim que os construtores se tornam deuses, os seus altares ${ }^{(9)}$ estão tão vazios, por falta de um sobrevivente, como (os dos) cansados, os mortos na represa (...). Procura um dia feliz e esquece os cuidados!»(10)

O debate deste duplo pessimismo - de uma parte campeando pelas concepções escatológicas e funerárias tradicionais («Eu»); de outra parte denunciando o descrédito que a «liberalização» e a «privatização» da religião acarretaram (ba) - encerra-se com um acordo de meio-termo: o «Eu» cessa os lamentos e o ba aceita ficar com ele de modo a aplacar-lhe a angústia de não ser aceite no Ocidente, o país dos defuntos.

$\mathrm{Na}$ Morte de Enkidu, o jogo argumentativo desenvolve uma oposição simples entre uma visão pessimista (Enkidu) e uma visão optimista (Gilgameš). Radicalizando-se logo após o primeiro sonho premonitório, Enkidu profere uma série de três maldições: à porta de cedro; ao caçador; à prostituta sagrada Chamhat.

As três maldições equivalem tanto a uma desvalorização de experiências passadas:

«Houvesse eu desconfiado, oh porta, que assim tu [me pagarias]»(11)

Quanto a uma exacerbação pessimista da situação presente e futura:

«Meu amigo, fixo [está o meu destino,]

a gente vai para a sua ruína antes do seu tempo»(12)

Contrapondo o pessimismo exacerbado de Enkidu, Gilgameš e Šamaš notam-lhe a importância fulcral que essas experiências passadas tiveram em tornar possível a sua hominização e as mais-valias associadas. 
É por essa via que o pessimismo de Enkidu é, parcialmente, superado. Ouvindo Šamaš, Enkidu concorda com influência positiva de Chamhat, nomeadamente ao aproximá-lo de Gilgameš, e reverte a maldição em bênção. Por outras palavras, revaloriza as suas experiências passadas e com isso consegue encarar a morte de modo menos angustiado.

Porém, Enkidu não cessa de ver negativamente o seu futuro, o encontro com o demónio Anzû, com a sua morte:

"Calcando [ele] esmagou-me, como um poderoso touro selvagem»(13)

Gradualmente, o protagonista é superado na sua argumentação sendo levado a concordar e a retratar-se ou é levado a atingir um meio termo, a, pelo menos, tolerar os argumentos da esfera optimista.

\section{Conclusão}

Posto isto, podemos concluir que as literaturas egípcia e mesopotâmica conheceram o fenómeno do pessimismo literário, disto são exemplo as composições Disputa sobre o Suicídio e Morte de Enkidu.

Em ambas as composições o pessimismo literário é utilizado como um recurso estilístico e encontra-se subordinado a uma determinada finalidade, respectivamente: o debate de duas concepções escatológicas; o contraste entre duas fases de vida.

De forma a servir essa finalidade, o pessimismo literário evoca a imagética negativa recolhida pela memória colectiva de fases dramáticas da história do contexto civilizacional.

Por outro lado, o pessimismo literário alicerça-se nas concepções antropológicas e escatológicas enraizadas no contexto civilizacional. Das semelhanças e diferenças destas concepções advêm as semelhanças e diferenças entre as duas composições que estudámos.

Em qualquer dos casos, podemos afirmar que o pessimismo literário existe para ser superado. No limite, tanto o contexto egípcio como o contexto mesopotâmico souberam tornar a sua propensão pessimista, induzida pela prevalência da morte, num motor de desenvolvimento criativo como sugere Morenz:

«Bien qu'elle lui ait été très présente et qu'il ait porté sur elle un jugement nettement négatif, la mort n'a pas écrasé l'Égyptien, mais a canalisé son instinct créateur et l'a aidé à faire une grande oeuvre.»(14) 


\section{Notas}

O presente trabalho temático foi elaborado no âmbito do seminário de Egiptologia do $2^{\circ}$ ciclo de estudos, leccionado pelo Professor Luís Manuel de Araújo na Faculdade de Letras da Universidade de Lisboa.

(1) «A Dispute over Suicide», tradução de John A. Wilson, pp. 405-407.

(2) «Lamentações e profecias: Diálogo do cansado da vida com o seu ba» in CARREIRA, Literatura do Egipto Antigo, pp. 91-98.

(3) «The Dispute Between a Man and His Ba», in LICHTHEIM, Ancient Egyptian Literature, pp. 163-169.

(4) «Littérature et Humanisme: Le pessimisme», in DAUMAS, La Civilisation de L'Égypte Pharaonique, pp. 400-405.

(5) Diversos autores sustentam que a XII tabuinha mais não é que um anexo inorgânico que terá sido incluído na mesma série bibliográfica por afinidades temáticas.

(6) «Tablet VII. The Death of Enkidu», in GEORGE, The Epic of Gilgamesh, pp. 54-62.

(7) Restaurada por Andrew George graças à prosa hitita.

(8) «A Dispute over Suicide» tradução de John A. Wilson.

(9) Literalmente: «as suas pedras-de-oferendas».

(10) «A Dispute over Suicide», tradução de John A. Wilson, p. 405.

(11) «Tablet VII. The Death of Enkidu», in GEORGE, Andrew; The Epic of Gilgamesh. London, Penguin Books, 1999. p. 56.

(12) «Tablet VII. The Death of Enkidu», in GEORGE, Andrew; The Epic of Gilgamesh, p. 57.

(13) «Tablet VII. The Death of Enkidu», in GEORGE, Andrew; The Epic of Gilgamesh, p. 60.

(14) «La mort et les morts», in MORENZ, La religion égyptienne, p. 256.

\section{Fontes}

GEORGE, Andrew; «Tablet VII. The Death of Enkidu» in The Epic of Gilgamesh. London: Penguin Books, 1999. pp.54-62.

LICHTHEIM, Miriam; «The Dispute Between a Man and His Ba» in Ancient Egyptian Literature. Vol. I. Berkeley and Los Angeles: University of California Press, 1975. pp.163-169.

PFEIFFER, Robert H.(trad.); «The Epic of Gilgamesh» in PRITCHARD, James B.; Ancient Near Eastern Texts Relating to the Old Testament, $3^{\mathrm{a}}$ ed. Princetown, Princetown University Press, 1969, pp. 85-89.

WILSON, John A. (trad.); "A Dispute over Suicide» in PRITCHARD, James B.; Ancient Near Eastern Texts Relating to the Old Testament, $3^{\mathrm{a}}$ ed. Princetown, Princetown University Press, 1969, pp. 405-407. 


\section{Bibliografia}

ALDRED, Cyril, "A primeira decadência e a recuperação durante o Império Médio», in Os Egípcios. Col. «História Mundi», [s/l], Editorial Verbo, [s/d]. pp.105-111.

ARAÚJO, Luís Manuel de (dir.), Dicionário do Antigo Egipto. Lisboa: Editorial Caminho, 2001 [Verbetes: Ba, Ka, Akh, etc.].

BOTTÉRO, Jean, «The Mythology of Death», in Mesopotamia. Writing, Reasoning, and the Gods. Chicago London: The University of Chicago Press, 1992, pp. 268-286.

CARREIRA, José Nunes, «Lamentações e profecias: Diálogo do cansado da vida com o seu ba», in Literatura do Egipto Antigo. Mem Martins: Europa-América, 2005, pp. 91-98.

COELHO, Ilda Sobral, "O Imaginário do Além», in Percursos do Oriente Antigo. Homenagem a José Nunes Carreira. Organização de José Augusto Ramos, Luís Manuel de Araújo e António Ramos dos Santos. Lisboa: Instituto Oriental da Faculdade de Letras da Universidade de Lisboa, 2004, pp. 121-137.

DAUMAS, François, «La Religion et la Pensée: La conception égyptienne du composé humain», in La Civilisation de L'Égypte Pharaonique. Col. Les Grandes Civilisations, Paris: Arthaud, 1977, pp. 252-256.

«La Religion et la Pensée: Les conditions de la survie d'après les textes funéraires» in La Civilisation de L'Égypte Pharaonique. Col. Les Grandes Civilisations, Paris: Arthaud, 1977, pp. 256-264.

«Littérature et Humanisme: Le pessimisme», in La Civilisation de L'Égypte Pharaonique. Col. Les Grandes Civilisations. [s/l], Arthaud, 1977, pp. 400-405.

DONADONI, Sergio, "O Morto» in Donadoni, Sergio (dir.) et alli, O Homem Egípcio. Lisboa, Editorial Presença, 1994, pp. 217-236.

JONKER, Gerdien, «The Topography of the Dead» in The Topography of Remembrance. The Dead, Tradition and Collective Memory in Mesopotamia. Leiden, New York, Köln, E.J.Brill, 1995, pp. 187-211.

LOPES, Maria Helena Trindade, «O Universo Religioso», in O Egipto Faraónico. Guia de Estudo. [s/l], Associação Portuguesa de Egiptologia, 2003, pp. 61-83.

MORENZ, Siegfried, «La mort et les morts» in La religion égyptienne. Paris: Payot, 1984 [1 $1^{a}$ edição de 1962]. pp. 239-274.

RACHET, Guy, Dicionário Temático Larousse. Civilizações do Antigo Oriente. Rio de Mouro: Círculo de Leitores, 2000. [Diversos Verbetes].

RACHEWILTZ, Boris de, “O Ritual Funerário», in A vida no Antigo Egipto. [s/l], Círculo de Leitores, [s/d]. pp. 109-123.

SANMARTÍN, Joaquin e SERRANO, Jose Miguel, «El subsistema cultural mitológico en la antigua Mesopotamia", in Historia Antigua del Próximo Oriente. Mesopotamia y Egipto. Madrid: Akal, 2008, pp. 80-102.

«Las formas de vida religiosa: creencias y prácticas», in Historia Antigua del Próximo Oriente. Mesopotamia y Egipto. Madrid: Akal, 2008, pp. 215-234. 